This is a post-referring version of a paper published as:

\title{
Saying something interesting about responsibility for health
}

Snelling, P. C. (2012). Saying something interesting about responsibility for health. Nursing Philosophy, 13(3), 161-178.

The published version is available at http://onlinelibrary.wiley.com/doi/10.1111/j.1466-769X.2011.00531.x/full

\begin{abstract}
The concept of responsibility for health is a significant feature of health discourse and public health policy, but application of the concept is poorly understood. This paper offers an analysis of the concept in two ways. Following an examination of the use of the word 'responsibility' in the nursing and wider health literature using three examples, the concept of 'responsibility for health' as fulfilling a social function is discussed with reference to policy documents from the United Kingdom. The philosophical literature on moral responsibility is introduced, and in considering two versions, reactive attitudes and accountability, it is argued that in application both can be regarded, though with different emphasis, as being constituted in three parts: (i) a responsible agent (ii) having obligations (responsibilities) and (iii) being susceptible to being held responsible (that is blamed) if he fails to meet them. The three stage model is consistent with the examples of the word responsibility in use, but application to the social function model causes a number of problems for healthcare practice, especially for the reactive attitudes account. Apart from considerable problems in stating what exactly the obligations are and how they can be justified; and how blame might justly be apportioned and by whom, the very ideas of obligation and blame are in conflict with healthcare systems and professional nursing practice which have foundations deeply embedded in the notion of the supremacy of personal autonomy. It is concluded that current application of the concept of responsibility for health is conceptually incoherent, and if it is to retain its place in health policy and discourse, urgent remedy is required.
\end{abstract}

Key words: Responsibility for health, Agency, Professional ethics, Obligation, Blame

\section{Dr Paul Snelling}

Principal Lecturer in adult nursing

Department of Nursing and Midwifery

University of Worcester

Henwick Grove

Worcester

WR2 6AJ

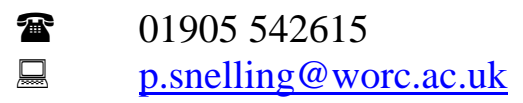


Saying something interesting about responsibility for health

\section{Introduction}

It cannot be said that the issue of responsibility for health is new (Reiser 1985), but current fiscal uncertainty, technological advances, and the unrelenting increase in the prevalence and incidence of illnesses related to lifestyle combine to give the issue renewed significance. Despite this, there is little in the nursing literature about what the concept of 'responsibility for health' consists of, and why it is so important and so difficult. The simple aim of this paper, following Paley (1996), is to 'say something interesting' about responsibility for health. I offer two analyses of 'responsibility' as applied to professional healthcare. First, I discuss examples of the use of the word 'responsibility' found in the nursing and broader literature. Second I consider the concept of 'responsibility for health' as fulfilling a social function. I then turn to the philosophical literature on moral responsibility, and in considering two versions, reactive attitudes and accountability, argue that in application both can be regarded, though with different emphasis, as being constituted in three parts: (i) a responsible agent (ii) having obligations (responsibilities) and (iii) being susceptible to being held responsible (that is blamed) if he fails to meet them. The three stage model is consistent with the examples in use, but application to the social function model causes a number of problems, especially for the reactive attitudes account. Apart from considerable problems in stating what exactly the obligations are and how they can be justified; and how blame might justly be apportioned and by whom, the very ideas of obligation and blame are in conflict within healthcare systems and professional nursing practice which have foundations deeply embedded in the notion of the supremacy of personal autonomy.

\section{Two concepts, many conceptions}

An obvious starting point is that the term 'responsibility for health' contains two distinct concepts, responsibility and health, and it might reasonably be suggested that combining them will obfuscate analysis. Health is variously understood, famously by Boorse $(1975,1977)$ and Nordenfelt (for example, 1996, 2007). In Boorse's account health is descriptively merely the absence of disease, defined in terms of statistical normality, while Nordenfelt's evaluative account understands health more holistically as the ability to realize life goals. These different conceptions can result in practical differences in healthcare all of which could justifiably claim to be directed at improving health (Nordenfelt 1993). Similarly, the concept 'responsibility for health' will differ depending on which account of health is utilised. To understand why this potential confusion need not cloud the analysis, it is necessary to be clear about the difference between concepts and conceptions.

The distinction is that conceptions lie lower in a vertical continuum between general and specific usages of a word. Conceptions offer a more 'determinate specification' (Miller 2010 p. 812) of the parent concept, operationalising and applying it. Inevitably this means that two or more conceptions can be derived from a single concept. Vertically each conception must be consistent with the parent concept or they will be conceptions of different concepts, but horizontally, between conceptions within a concept, there may be incommensurable differences. Where this happens we have, following Gallie (1956) 'essentially contested concepts'. Gallie had in mind artistic and political concepts (Ruben 2010), but it has been suggested that medicine meets the necessary criteria (McKnight 2010) set out at some length by Gallie. A further 
relevant example is discrimination, used differently by the UK governing bodies of nurses and doctors. Nursing's professional regulator, the Nursing and Midwifery Council (NMC) (2008) states that 'You must not discriminate in any way against those in your care. ${ }^{1}$ ' The UK medical regulator, the General Medical Council (GMC) states that 'You must not unfairly discriminate...'(GMC 2006 p.10). Whilst operationalising a concept fundamental to professional healthcare practice, the two regulators have used different conceptions of the same concept; the NMC has used the word evaluatively, while in using the word descriptively, the GMC requires an evaluative adverb. It is not suggested that doctors treat patients differently (though it could be suggested), only that different conceptions of the concept 'discrimination' have resulted in a position where on application of the verb 'to discriminate' separate from evaluative adverbs, doctors are potentially able to do something that nurses are not, that is discriminate fairly (Hellman 2008, Moreau 2010). ${ }^{2}$

Argument about which conception is correct is ultimately futile as each can be derived from the parent concept, and this is potentially a problem, though rarely acknowledged, for inductive concept analysis methodology which may attempt an improbable synthesis between these essentially contested conceptions ${ }^{3}$. Similarly, different conceptions of health are important in operationalising conceptions of 'responsibility for health', but ambiguity is manifested in the conceptions rather than the parent concept. Insofar as the task of this paper is to say something interesting about the parent concept, rather than any specific operationalising conception, the analysis is more fruitfully directed at the concept of 'responsibility'. The importance of the different conceptions of health lie in determining obligations, outside the scope of this paper.

\section{Work required of the concept}

The justification of undertaking an analysis and the methodology employed depends on the work the concept is required to $\mathrm{do}^{4}$. One purpose could be to undertake concept analysis to explore what responsibility for health (or more broadly 'responsibility' within the healthcare environment) means to individuals, with the aim of arriving at a composite definition which could be used in further research.

\section{Concept Analysis (1) Responsibility in use}

Anyone wishing to clarify any concept relevant to nursing practice has a large and growing body of work to build upon. Despite substantial critiques from, inter alia, Paley (1996), Beckwith et al. (2008) and Risjord (2009), the proliferation of concept analyses in nursing journals shows little sign of abatement. It is perhaps surprising that many published examples show little appetite for engagement with the ontological, epistemological and (perhaps most surprising) methodological problems identified in the critiques, following instead a substantially standardised process rarely found outside the nursing literature. Were Walker \& Avant's (2011) concept analysis

\footnotetext{
${ }^{1}$ In England and Wales the National Health service as a whole takes this evaluative line in the NHS constitution

${ }^{2}$ In English law under the Equality Act 2010 Discrimination requires less favourable treatment

${ }^{3}$ None of the 1261 'hits' in a BNI and CINHAIL search ( $1^{\text {st }}$ February 2011) referenced Gallie's paper (The number of hits would include some identified twice).

${ }^{4}$ Walker \& Avant (2011 p.160) suggest that it could be a concept that 'has always bothered you.'
} 
procedure to be followed, the literature, dictionaries and theses would be searched towards the aim of arriving at 'a precise operational definition' (p. 158); the result of answering the empirical question " how are the words 'responsibility for health' used", rather than an analysis of the concepts denoted by the words (Wedgwood 2005). Unfortunately many of the relevant papers found using the term 'responsibility' ${ }^{5}$ manage to discuss and use the term without saying what it means. Three examples illustrate this; adolescent diabetes, women's magazines, and public attitudes to health care policy ${ }^{6}$.

In the US, Anderson et al. (1990) developed a widely used questionnaire to measure 'individual family member's perceptions of who takes responsibility for a broad range of diabetes tasks' (p. 479). The questionnaire asks participants to choose from a list of 3 choices against a number of situations or tasks, for example 'remembering the day of clinic appointment.' The options are;

1. Parent(s) take or initiate responsibility for this almost all of the time

2. $\quad$ Parent(s) and child share responsibility for this about equally

3. Child takes or initiates responsibility for this almost all of the time.

Within the paper, the choices are explained so that 'the respondent assigned a 1 if the parent was predominantly 'in charge' (p. 481) of the task. It should be clear that I am not criticising the paper, merely pointing out that the term 'responsibility' apparently needs no explanation as none was offered to those completing the questionnaire. It is assumed that they know what it means, and what is available in the text by way of explanation refers in passing to being 'in charge.'

This paper is one of many analysed in Hanna \& Decker's (2009) concept analysis of 'assuming responsibility for self-care among adolescents with type 1 diabetes.' Similarly there is no discussion about what 'responsibility' means in the general sense. The conclusion of the analysis is that the attributes of assuming responsibility include that it is '...(c) a process with the goal of ownership and (d) a process involving autonomy in behaviours and decision making' (2009 p.101). The model case (part of Walker \& Avant's (2011) procedure) offered is a fictional 17 year old who says that she 'will be fully responsible when she is able to be totally independent in doing all the diabetes care tasks and being the one who makes the decisions about them without any reminders' (p.102). Olinder et al. (2011) report a grounded theory study utilising interviews with adolescents where responsibility emerged as a core category and provided the principal ingredient in a model to facilitate the clarification of responsibility. They state that (2011 p.5) 'A lack of responsibility seems to be a main reason for missed bolus doses and insufficient self management', but this has several potential meanings.

\footnotetext{
${ }^{5}$ Using the databases, CINHAIL and MEDLINE (14 ${ }^{\text {th }}$ November 2011$)$, there were 11475 'hits' searching for 'responsibility' in the title, and 1123 'hits' searching for 'responsibility for health' in the title. A full analysis or categorisation of all sources identified was not undertaken. A partial but unsystematic review suggested that many of the papers identified were not relevant to the argument presented in this paper.

${ }^{6}$ The examples were chosen because they illustrate the points I wish to make. I do not claim that these papers are in any sense representative,
} 
Second, in a fascinating account of the discourse about responsibility for health in English - Canadian women's magazines, Roy (2008) shows how the discourse reinforces 'neo-liberal ideas by conceptualising responsibility for one's health as not only something that can be chosen but something that ought to be chosen' (p. 473). The discourses not only cover the familiar path of health promotion, but also urge that women be determined in pushing agendas in relationships with physicians and to be brave in the face of debilitating illness; 'constructing continued optimism as an important moral obligation, how one with a disease or disability ought to behave (p. 472).' In one reviewed article a woman with multiple sclerosis defines responsibility as '... accomplishing the things I wanted in life right now. Today' (MacLean $1999 \mathrm{p}$. 73, cited in Roy 2008 p. 471). This seems to be a somewhat idiosyncratic understanding of responsibility, re-emphasising potential pitfalls of inductive analysis. The paper generally presents an idealised understanding of responsibility promulgated in the magazines which, in claiming robust obligations whilst failing to address or even acknowledge barriers to meeting them, might be considered more moralistic than moral. The paper does not engage in a discussion about what the concept of responsibility means in general, focussing instead on the various conceptions presented, but the title resonates with the work on teenagers with diabetes; 'Taking charge of your health': discourses of responsibility in English-Canadian women's magazines'.

Third, in the UK, the King's Fund (2004) commissioned a survey to assess public attitudes to health policy. In the quantitative phase a series of yes/no questions were presented. ' $88 \%$.... agreed that individuals are responsible for their health' (2004 p. $11)^{7}$. However, more than ' $40 \%$ agreed that there are too many factors outside individual control to hold people responsible for their own health' (2004 p. 11). The questionnaire does not appear ${ }^{8}$ to explain what is meant by responsibility for their health, but the high rate of agreement suggests that respondents understand what is meant.

There is no indication in any of three examples that the lack of definition or explanation of responsibility has caused problems; evidently those who answer the questionnaires have something in mind, but the form of the questions and the way that they are reported give little indication of what more detailed understandings might be. These incomplete understandings, even when they represent everyday usage make a nuanced inductive concept analysis problematic. I shall return to these partial accounts, but for now I turn to a second use of the term, which recognises that some concepts have broader social functions (Miller 2010).

\section{Concept Analysis (2) Responsibility as social function.}

The concept 'responsibility for health' fulfils an important social function within socialised medicine, and is used for example in policy documents to explain respective roles within that system ${ }^{9}$. In this context, clarifying meaning cannot be a matter for inductive analysis of partial usage because the concept is required to do the work of providing a framework for helping people to understand just what it is that

\footnotetext{
${ }^{7}$ Elsewhere in the published document this figure is given as $89 \%$

${ }^{8}$ The actual questionnaire used is not reproduced in the publication

${ }^{9}$ In fact the broad term responsibility is increasingly heard in myriad social and political contexts for example in welfare provision (Brown 2010, Maltravers 2007)
} 
they should or must do, and this social function cannot be fulfilled unless the recipients of the message understand what having 'responsibility for health' requires. Inductive analysis of the word 'responsibility' in use may give insight into how the message is variously received but that does not abolish the need for clarity in its transmission. An objection that it is not for the Government to tell us, for example, that we ought not to smoke would be to confuse the global concept of responsibility with its determinative conceptions. However, rejecting one or many conceptions does not entail rejection of the concept and understanding of the determinative conceptions requires a general understanding of the concept. If this is the case, and the concept 'responsibility for health' does form a social function within socialised ${ }^{10}$ medicine, then there should be clarity about what this means. A cursory glance at National Health Service documents reveals that this is not the case.

The (former) Prime Minister's ${ }^{11}$ introduction to the strategy to reduce obesity provides a clear statement which illustrates the confusion;

There should be no doubt that maintaining a healthy weight must be the responsibility of individuals first - it is not the role of government to tell people how to live their lives and nor would this work.

(Department of Health 2008 p. iii)

First the Government tells us what we must do (maintain a healthy weight), and then it tells us that it is not their role to tell us how to do it. The relevant clause in the NHS constitution ${ }^{12}$ states that;

You should recognise that you can make a significant contribution to your own, and your family's, good health and well-being, and take some personal responsibility for it.

(Department of Health 2009 p.9)

Similar to the literature reviewed earlier, this leaves the meaning of 'responsibility' open to interpretation, particularly within the phrase 'some responsibility', and the normative prescription simply requires recognition that a significant contribution is possible, and not that it be made. Further explanation is provided in the handbook to the constitution. Entitled 'what this means in practice', the clarification is;

You can talk to your doctor, nurse (including health visitors and midwives) or therapist, use NHS Direct (online at www.nhsdirect.nhs.uk or telephone 0845 4647), or go online at NHS Choices (www.nhs.uk). You can ask about what support you might be offered in managing your condition yourself or changing to a healthy lifestyle (e.g. stopping smoking, reducing weight, exercise or reducing excessive alcohol consumption).

\footnotetext{
${ }^{10}$ The UK National Health Service is possibly the paradigm case of socialised medicine. The drawing on collective resources for treatment might provide a reason for the view that certain health enhancing behaviours are morally obligatory, but not the only reasons. I do not mean to suggest that the concept responsibility for health has no meaning within private health care systems.

${ }^{11}$ The Prime Minster at the time was Gordon Brown.

12 The constitution applies to NHS services in England and Wales
} 
Saying something interesting about responsibility for health

(Department of Health 2010 p. 67)

This explanatory note falls considerably short of explaining either the nature or the details of responsibility ${ }^{13}$, and by utilising language which hints at information giving (you can), the clarification sets a rather different tone than the normative clause (you should) in the constitution, and the imperative (must) in the Prime Minister's introduction to a previous document. Having identified its social function, the guidance fails to guide. The Scottish NHS version initially goes further. Under the heading 'What we expect from you' it is stated that;

'You can help yourself, other patients and NHS Staff if you do the following;' Look after your own health and have a healthy lifestyle. This could mean; taking more exercise, eating a balanced diet, stopping smoking, not drinking too much alcohol, not using drugs, and using a condom if having sex.'

The NHS Scotland (2005 p.15)

Though the heading is stated as an expectation, the language in the text is softer (you can help yourself). Similar internal ambiguity is evident in the Report of the Prime Minster's Commission on the future of Nursing and Midwifery in England (2010). Recommendation 13 (2010 p.102) includes the statement that;

Nurses and Midwives must acknowledge that they are seen as role models for healthy living and take personal responsibility for their own health.

(Prime Minister's Commission...2010 p.102)

The language is declamatory (must), but the proposed draft pledge less so;

Nurses and midwives, recognising our important role in improving health and wellbeing and reducing inequalities, will engage actively in the design, monitoring and delivery of services to achieve this. We acknowledge that we are seen as role models and will try to live up to this responsibility.

(Prime Minister's Commission...2010 p.57)

The response was delayed because of the general election and subsequent change in government. Despite the sentiment, expressed by the Minister, that the report 'does not go far enough' (Department of Health 2011 p. 5) the recommendations noted above will not be implemented in full. The section of recommendation 13 requiring that nurses take personal responsibility for their own health is ignored; the response is restricted to the implementation of the Boorman report (Boorman 2009) 'NHS Health and Well-being' which recommended a less prescriptive provision of services centred on prevention 'of both work related and lifestyle influenced ill health' (p. 29). The recommended pledge will not be implemented. Instead, 'Employers need to use the Principles of Nursing Practice as a pledge...' (Department of Health 2011 p.6). These Principles, developed and published not by the regulator but by the Royal College of Nursing (RCN) (Manley et al. 2011), a union representing less than two thirds of

\footnotetext{
${ }^{13}$ the document is addressed to 'Patients and the public'
} 
registered nurses, do not acknowledge nurses as role models in a public health sense. Though the Commission's relevant recommendations will not be implemented, the fact that they attracted such wide support from the nursing 'establishment' (including the Department of Health's Chief Nursing Officer, the RCN and the NMC) lends them considerable authority, and the watered down response, facilitated by the same organisations, is further illustrative of the general confusion.

To recap; I have offered two possible accounts of how responsibility for health might be understood and analysed. The first account, which could be deepened by inductive concept analysis, is or could be theory forming, empirical and stems from ordinary usage of the word by members of the public and patients who answered questions about responsibility. It is incomplete rather than inadequate in its expression. The second is theory formed and normative but requires clarification and deeper understanding to be effective. The policy examples demonstrate that the concept has a social, action guiding function but there is no clarity about what is required and the mixed messages illustrate an account which is as inadequate as it is incomplete. The task for the remainder of this paper is to argue that the two accounts I have offered are not incompatible, and that they and other usages of 'responsibility' can be unified under a broader understanding of what responsibility for health means, and I proceed by introducing the philosophical literature on responsibility. Though this may provide a richer application of both of the accounts I have offered, philosophical illumination also reveals incoherence at the heart of healthcare provision and practice; attempting to avoid this incoherence may be one cause of the partial accounts populating the literatures.

\section{The philosophical literature.}

\section{Causation.}

Causation plays a major part in responsibility. When we say that $\mathrm{X}$ was responsible for $Y$, meaning can be restricted to $X$ caused $Y$. The causal claims can include nonmoral and even inanimate objects. We say that ice was responsible for the collision, or the red sock was responsible for the pink washing. When we ask 'who is responsible for the broken window?', we ask how the window came to be broken. A small child throwing a stone is superficially and causally responsible for the broken window, but not, in Sie's (2005) categorisation, deeply morally responsible because he is not a moral agent. Causation is also key in the relationship between being responsible for a thing and being responsible for our acts and omissions in relation to the thing. When we say that we are responsible for our health we cannot mean that we are responsible for all aspects for our health at all times. If ill health results from being struck by an asteroid, nothing that we did or omitted to do caused the injury. It could be said that my omission to be elsewhere was a factor but this is only relevant in the deeply morally responsible sense if I knew and understood that I was going to get hit, and that therefore I ought to have gone somewhere else to avoid it.

Causative links between actions or omissions and poor outcomes for the things that we are responsible for are central to the question of what we ought to do to keep well, and why. A group correlation between smoking and heart disease does not mean that all heart disease is caused by smoking, or even that the heart disease of smokers was caused by smoking. Smoking, though correlated with heart disease is neither 
necessary not sufficient for individual instances of heart disease. Inevitably the devil is in the detail for specific causative factors for specific diseases, but for this paper, it is enough to note that discussion about responsibility for health, involves deep, moral responsibility as well as superficial causal responsibility, and that because of the lack of certainty of individual causation it is not health per se that we are responsible for but rather our actions or omissions that threaten or enhance it.

\section{Other forms of responsibility}

H.L.A. Hart (1962) and others (for example, Cane 2002) have pointed out that responsibility comes in many forms, for example role responsibility and legal responsibility ${ }^{14}$. It is important to distinguish between the various forms of responsibility, especially where they coincide. Consider the various forms of responsibility as they relate to $\mathrm{Z}$, a user of heroin. Let us assume that $\mathrm{Z}$ has entered into an agreement (contract) with the healthcare team that he will not use heroin, and that if he does there is a consequence, say that he will be discharged from a rehabilitation unit (Houmanfar et al. 2008). We know that there is a law ${ }^{15}$ prohibiting the possession of heroin, and so if he is found in possession he is liable to prosecution. For quasi-contractual ${ }^{16}$ and legal responsibility we can examine the agreement, or identify legislation or case law, and these are clear in defining what $\mathrm{Z}$ is obliged, contractually or legally to do (or not to do), as well as identifying what will happen to him if he fails in this responsibility.

There may be moral reasons for $\mathrm{Z}$ to avoid using heroin (Smith 2002), and no doubt these have influenced decisions that have made possession of heroin unlawful and the therapeutic contract acceptable. Fines and imprisonment may result from a breach of a legal responsibility, and discharge from rehabilitation results from a breach of the agreement. That these breaches may also represent moral failure is contingent but not necessary. Moral responsibility differs in at least two respects here. First there are no unequivocal moral facts about taking heroin that make it absolutely the case that it is immoral ${ }^{17}$. Many would hold that taking heroin is wrong and cite reasons in support, but there is also a view that taking heroin is morally permissible. Other health threatening behaviours also attract differing views about whether they are morally forbidden, allowed or (in some cases) obligatory or morally neutral. It cannot be said that taking heroin is immoral with the same certainty as it can be said that possessing heroin is unlawful. $\mathrm{Z}$ cannot deny the legal and quasi-contractual responsibility not to take heroin, but he can take the view that there is nothing morally wrong with it. ${ }^{18}$

Second, the consequences for failing to meet legal and contractual responsibilities are clearly articulated, but this is not the case when failing to meet a moral responsibility.

\footnotetext{
${ }^{14}$ These refer to various sorts of responsibility attached to individuals, but we also talk about collective responsibility and responsibility of institutions. (Wilmot 2000, Dubbink \& Smith 2011)

15 The Misuse of drugs Act 1971 provides for a maximum sentence of seven years imprisonment for possession of a class A drug (including heroin).

${ }^{16}$ I say quasi-contractual because I do not want to imply that the sort of agreement that I refer to is necessarily a legal contract.

${ }^{17}$ This is not the place to discuss whether there can be moral facts or whether, if there can, it is true that taking heroin is wrong.

${ }^{18}$ He cannot deny that the law prohibits possession, but he can argue that it ought not to. The relationship between law and ethics is far too complex to discuss in detail here, and I have taken a very simple line to make the point.
} 
The relationships between an agent, his moral obligations and the consequences of not meeting them form the basis of the philosophical concept of moral responsibility. Two versions are briefly reviewed; reactive attitudes and accountability.

\section{Moral responsibility (1) Strawson and the reactive attitudes}

You cannot go very far into the philosophical literature on responsibility without encountering Peter Strawson's influential lecture and paper, Freedom and Resentment, first published in 1962. The paper's aim is to argue that our normal practices of moral responsibility are 'underpinned by reasons that are immune to the threat posed by determinism' (Maltravers 2007 p.34). Determinism is the theory that everything that happens is determined by the things that precede it and the natural laws of physics. If true, this would effect the way we regard the things that people do, for despite our weighing up options and reflecting on our choices (both of which are also determined), we only end up doing the things that we would have done. Our part in the causal chain is fixed; choice is illusory, we can only do the things that we are determined to do. Incompatibles (Van Inwagen 1975) argue that if determinism is true, we cannot be morally responsible for the things we do ${ }^{19}$. Compatiblists, like Strawson, argue that moral responsibility obtains even if determinism is true.

Fully causal determinism is virtually absent in the literature on autonomy and responsibility in healthcare, possibly because the idea of a fully determined life is so difficult to comprehend. There appears to be at least a compatiblist assumption if not an outright assumption of the falsity of determinism despite what Wallace (1994 p.58) refers to as 'the seductiveness of incompatiblism'. Nelkin (2007, and see Kane 2005) cites several influential sources for the view that intuitively we start as incompatiblists; 'we are incompatiblists before we (compatiblists) start studying philosophy and talk ourselves out of it (2007 p.244)'. She proceeds to discuss a number of areas where intuitions tested empirically are inconsistent, and the view emerges that that we are instead compatiblists by inclination. In contrast to the absence of causal determination in the literature, other less complete forms of determination, for example, genetic, social and environmental are highly visible in the sense that these influences, whose effect on behaviour is correlated at the societal level (Raphael 2006) can be suggested to threaten and impede moral agency and therefore responsibility. The question must be suggested; if our natural inclination (if we have one) is to be compatiblist in the matter of causal determinism, must consistency require that we also be compatiblist in the matter of genetic, social and other determinist mechanisms which fall short of full causation? This is hinted at in the King's Fund report (2004), which is incompatiblist in its reporting, if not its data. Nelkin's examples of inconsistency in intuitions support the view that individually and collectively humans are not as rational or consistent as we may hope or believe and this threatens arguments premised on intuition claims and reflective equilibrium (and see Sutherland 1992, Thaler and Sunstein 2009). The often repeated view that more research is necessary seems for once to be fully justified.

Strawson's (1962) paper is relevant not so much because of its compatiblist emphasis, but rather in the claims about the purposes and nature of moral responsibility. Moral

\footnotetext{
${ }^{19}$ Here the incompatibility is between freewill and determinism, but since moral responsibility requires freewill, moral responsibility and determinism are also incompatible in this account.
} 
responsibility is based on the reactions of other people to our character and actions. When we are wronged we feel certain reactive attitudes towards wrongdoers; resentment and indignation. Generally people care about what others think of them, and wishing to avoid being thought of badly is a powerful social regulator of behaviour. The significance of the paper, and those that developed the ideas, lies in the view that individuals are responsible for those things that elicit the reactive response in the wronged. Being responsible is understood in the fact and process of being held responsible. Strawson was at pains throughout the paper to base his views on what he called 'common places', what we might consider as common morality, something which he says is easy to forget when we are engaged in philosophy. Other compatiblists (optimists as he calls them) have argued from consequentialist calculation that our practices of holding people responsible operate to regulate behaviour in socially useful ways, but that is to over-intellectualise the process;

what is wrong is to forget that those practices, and their reception, the reactions to them really are expressions of our moral attitudes and not merely devices we calculatingly employ for regulative purposes (emphasis in original).

Strawson (1962 p.93)

His claims about the practices of holding people morally responsible as well as their compatibility with determinism (should it be true) are based on ontological rather normative premises. There are exceptions in our practices for those, like children, or expressed in the language of the time, an 'idiot or a moral idiot' (p.82), and a recognition that a lack of intention also ameliorates the reactions.

Such reactive attitudes form part of the fabric of inter-personal relationships, but there are also vicarious attitudes felt by individuals not directly affected by wrongdoing. Instead of resentment we feel indignant or disapproving. We feel these attitudes of those who lie, distinct from and weaker than the resentment that we feel against those who lie to or about us. The moral demand here is that individuals should refrain from lying $^{20}$, but in the general sense, these vicarious attitudes speak to the nature of all moral expectation and define them in terms of an emotional response.

But these attitudes of disapprobation and indignation are precisely the correlates of the moral demand in the case where the demand is felt to be disregarded. The making of the demand is the proneness to such attitudes (emphasis in original)

(Strawson 1962 p. 90)

As the author of a relatively short if very influential paper Strawson left it to others to develop the ideas (for example Fischer 1987, Kahn 2011) R. Jay Wallace (1994 p. 226) deepened the account in several ways, concluding that;

It is reasonable to hold agents morally accountable when they possess the powers of reflective self control; and when such accountable agents violate the obligations to which we hold them they deserve to be blamed for what they have done.

\footnotetext{
${ }^{20}$ I put to one side for the moment the issue of whether lying can be justified or even required.
} 
Wallace (1994) also develops the nature of the obligation that is a necessary feature for responsibility in his account. Having the reactive emotions as a justifiable response to an action relies on the cause of the emotions having certain moral features such that the agent ought not to have done it. Or, he has failed to do something that he ought to have done ${ }^{21}$. An agent can be responsible for a morally neutral act; he is a rational candidate for praise or blame even if the act is worthy of neither. Whilst retaining the link between the act and a response, Fischer's (1987) account emphasises the features of moral agency which make a person legitimately blameable. The extent to which he is held responsible depends on the nature of the act he is responsible for. If it is morally neutral, holding him morally responsible is inappropriate, even though he is morally responsible for it in light of his moral agency.

\section{Moral responsibility (2) The accountability version}

The quotation from Wallace (1994) appears to go some way towards the accountability version of responsibility. Korsgaard (1992 p. 306) notes the unattractiveness of taking 'the assessment of others as the starting point in moral philosophy', and Oshana's (1997) alternative approach avoids working backwards from response. On this 'accountability' version of responsibility, a person is responsible if it is fitting that she give an account for her behaviour. This entails the presumptions that the individual has;

(a) antecedently met the requirements of responsible agency

(b) has performed some act (or has exhibited some characteristic) of the sort subject to certain accepted standards of morality

(c) typically has fallen short of these standards.

Oshana (1997 p.77)

Fittingness implies that it is not necessary for the individual actually to give an account; it is enough that it is appropriate. Similar to the reactive attitudes approach there are exceptions for those who are not full moral agents; we could not ask someone with dementia or a small child to account for themselves any more than we would appropriately feel resentment towards them. In the case of direct wrongdoing it seems clear that an account is owed to the wronged, but it is not so clear to whom the account corresponding to vicarious disapproval in the reactive attitudes approach, is owed. Regardless of whether the account is actually given, Oshana (1994) claims that the approach has the advantage of focussing firmly on the agent and what he has done, placing the burden upon the actor, regardless of the reactions of others.

There are clear differences between the reactive attitudes and the accountability versions of the nature of moral responsibility. Consider Agent A, undertaking behaviour $\mathrm{B}$ which elicits responses $\mathrm{C}$. In the reactive attitudes version, the responses $(\mathrm{C}(\mathrm{ra}))$ consist of indignation, or objectively, disapprobation from others, a consequence of $\mathrm{B}$ in the sense that it has occurred after $\mathrm{A}$ has undertaken $\mathrm{B}$, and is a result of $\mathrm{B}$. A is morally responsible for $\mathrm{B}$ because $\mathrm{C}(\mathrm{ra})$. In the accountability version the process follows the other direction. We say if $\mathrm{A}$ has certain properties, and $\mathrm{B}$ is

${ }^{21}$ See Harris (1980) on the equivalence of acts and omissions 
wrong, then he is liable to consequences $(\mathrm{C}(\mathrm{a}))$ in the form of being required to give an account. $\mathrm{A}$ is responsible for $\mathrm{B}$ therefore $\mathrm{C}(\mathrm{a})$.

There are many caveats in both versions but for now it is sufficient to draw attention to the similarities between the versions of responsibility rather than identify and unpick the differences. These similarities do little more than identify the constituent parts, but this is enough to expose the inadequacy of the concept in current usage within healthcare. These constituent parts or facets (Guttman and Ressler 2001), are a person, an act (or omission), and a reaction or a consequence. Or, a responsible agent who has responsibilities, and can be held responsible. These three constituent parts are implied in any discussion of any type of responsibility, though the reactive attitudes are distinctive features of moral responsibility.

\section{Applying the framework to the case studies}

I considered three examples; teenagers with diabetes, Canadian women's magazines, and the Kings Fund Report. Does the three stage analysis extend understanding in these cases? In the first, the teenagers are on the cusp of full moral agency. The narrative concerns 'taking charge' or accepting responsibility ${ }^{22}$. The responsibilities are the obligations detailed in the questionnaire, turning up for clinic appointments, remembering to take medication and so on. Absent from the account is any consideration of the consequences of failing to meet the obligations though it seems plausible that a teenager neglecting to take medication may be subject to some reactive emotions at least from her parents. Olinder et al. (2011 p.6) briefly consider this but only to the extent that 'nagging and criticism are not wanted. Sometimes they just want to be reminded, rather than asked why their blood sugar is high.' The Canadian magazines' narrative appears to assume moral agency in their readers. There is clearly some notion of obligation but little acknowledgement of consequences, though the moralist stance employed implies that those failing in their obligations will be thought less of. The King's Fund report considers and rejects the notion of full moral agency, does not engage in any sense in what health related obligations might be and seeks to restrict the consequences of failing to meet these unspecified obligations on the grounds of incomplete agency.

All we can say from the potential inductive process is that the three stage analysis is not inconsistent with the three examples, and it is unclear how the three stage analysis could have been arrived at by an empirical study of use of the word responsibility. How does the three stage analysis illuminate the second use of responsibility that is its use as an action-guiding concept within health policy?

\section{Applying the framework to Health Policy}

It is fair to say that there has been some controversy in the application of the political concept of personal responsibility in a number of policy areas. As far as health (and welfare) is concerned the notion is perhaps more popular and developed in the AngloAmerican post war tradition than on the European continent, though it appears to be gaining ground in Europe where, paradoxically perhaps, socialised medicine is less developed than in the UK (Schmidt 2007, Ter Meulen \& Maarse 2008). As far as the

\footnotetext{
${ }^{22}$ See Waller (2005) on the difference between 'take-charge' and 'just deserts responsibility'
} 
emphasis on personal responsibility is concerned, policy appears to assume agency, is confused in the matter of obligation and has consistently ruled out overtly holding patients responsible. We will see that the ground is characterised by difficulties and apparent paradoxes problematising each stage of the application of the concept. In identifying some of these I assume that despite the rhetoric, individuals are not currently held (morally) responsible for their health or their health threatening behaviours, and so the question offered for more detailed analysis elsewhere is not in what ways are individuals responsible for their health within the system of socialised medicine, but why are they not? ${ }^{23}$ We will look briefly at each stage in turn.

\section{Moral agency.}

Workaday application of autonomy in healthcare understood minimally as a commitment to informed consent belies the complexity of the various conceptions (Coggon 2007, Oshana 1998). Allmark (2008 p. 41) defines individual autonomy as 'the capacity of the individual to make and act upon judgments for which he is held morally accountable.' If this is the case, the result of the equivalence of autonomy and accountability (or responsibility) could reasonably be expected to conclude that if a patient is considered to be sufficiently autonomous to be allowed to buy cream cakes, or to consent to weight reduction medication or surgery, then he is also sufficiently autonomous so as to be liable to be held responsible for his eating and the obesity which follows, regardless of the multiple factors which influence eating behaviour, recognised by the UK government it its foresight report (Butland et al. 2007).

Oshana (2002) argues that the solution to this apparent paradox is that the equivalence of autonomy and responsibility is mistaken. A morally responsible agent has to be capable of normative competence as well as well as being able to act on desires and intentions. She gives the example of two versions of Hitler, the first version of which is incapable of recognizing any moral code which prevents him ordering genocide. She regards this first version of Hitler as not being a responsible agent, different from the second version who does recognise moral reasons for not ordering genocide but allows then them to be overruled. Punishment for the first version, that is holding responsible, must be justified by solely by referral to the utilitarian ${ }^{24}$ approaches that Stawson (1962) and others opposed. This is an extreme example perhaps, likely to test the credibility of the reflective equilibrium approach, which should capture our ${ }^{25}$ intuitions in clear cases (Fisher and Ravizza 1998). The obese cream cake eater may not acknowledge the second helping as a moral wrong, but that does not mean that she is incapable of doing so. The example of the Hitlers makes the point that responsibility requires additional features especially concerning rationality, and these additional features do not figure in considerations of deciding whether a person is sufficiently autonomous to consent to treatment. In the UK, capacity is decided upon by application of tests outlined in the Mental Capacity Act [2005] which determine ability to understand and retain information and use it to make a decision. The

\footnotetext{
${ }^{23}$ I am confident that many of us are held (morally) responsible within close interpersonal relationships but this lies outside the inquiry on moral responsibility within socialised medicine.

${ }^{24}$ As far as utilitarian accounts are concerned, it is possible to punish an innocent man (in the sense that he is not fully morally responsible) in the pursuit of greatest utility.

${ }^{25}$ I am never sure when philosophers say 'our' as in should capture 'our moral intuitions about clear cases' whether they mean their individual intuitions, or the intuitions of people in general - and if the latter what evidentiary support is available
} 
rationality of the decision lies outside the process, reflected in Lord Donaldson's famous observation that the absolute right to autonomy '... exists notwithstanding that the reasons for making the choice are rational, or irrational unknown or even nonexistent ${ }^{26}$ (Brazier and Cave 2011 p.118). Oshana (2002) claims that the error in lumping together autonomy and responsibility stems in part from a conflation of the global state of being autonomous with a locally autonomous act. The tendency to think of the former as being tied to responsibility results from the close ties between the latter and being responsible for the act in question. Workaday understanding of autonomy in healthcare very firmly concerns the latter.

Conversely, in discussing moral autonomy Dworkin (1988 p.35) states that 'A person is morally autonomous if and only if he bears the responsibility for the moral theory he accepts and the principles he applies.' And of interest is the view expressed in the UNESCO (2008) Bioethics core curriculum ${ }^{27}$ that

'In ethics the notions of autonomy and responsibility are mutually related. There is no autonomy without responsibility; beyond responsibility, autonomy turns to arbitrarity which means that the person in his/her decisions does not take into consideration the interests of others.

(UNESCO 2008 p. 27)

The relationship between responsibility and autonomy is too complex to be discussed in depth here, and my aim is simply to argue that there is a prime facie case for the view that if a person is considered autonomous then she is also responsible. Nevertheless, mainstream bioethics and liberal political opinion acknowledges limitations to responsibility for example in genetics (Levitt and Manson 2007), the neuroscience of decision making (Burns and Bechara 2007), and the language of addiction wider than drug use (Foddy 2011), whilst simultaneously promoting autonomy in the same persons. If patients are not held to account for their (allegedly) autonomously enacted health threatening behaviour then we must look further than moral agency to enquire why.

\section{Obligation}

Williams (2008) argues that philosophers usually discuss responsibility retrospectively, that is holding responsible, or consider the features of moral agency. Stawson's (1962) account is premised on the relationship between the agent and the response, and the technique of reflective equilibrium testing intuitions about clear cases. A clear case, for example tests intuition of, say a cat knocking over a vase. Our intuition tells us that we do not hold the cat responsible because it is not a moral agent. We have different reactive attitudes and to different extents if a small child knocks over the vase or if a passer-by twists her ankle and stumbles into it accidentally; we reserve full indignation for an autonomous person acting recklessly, or worse, maliciously. The attitudes we feel tell us something about what we think

\footnotetext{
${ }^{26}$ The case was Re T (Adult: Refusal of Medical Treatment) [1992] 4 All ER 649, CA

${ }^{27}$ The UK ethics curriculum for medical students includes that students 'be able to demonstrate a critically reflective understanding of the rights and responsibilities of patients and possible justifications for limiting their rights' (Stirrat et al 2010 p.57). There is no equivalent curriculum for UK nurses.
} 
about the agency of the person or the circumstances of the action, whether there was coercion, or constraint or just bad luck, or whether the vase was appropriately protected by its owner. The purpose of these thought experiments is to test our intuitions about moral agency, but there is another explanation for a failure to experience the reactive attitudes; the act may be morally neutral, and this seems important in an attempt to apply the reactive attitudes account of responsibility to healthcare provision. Many people would fail to feel disapprobation against smokers, not because they doubt agency (though they might), but because they think that there is nothing wrong with smoking.

We may conclude from this that the reactive attitudes approach to moral responsibility, notwithstanding Strawson's ontological claims, does not really help in understanding the social function of responsibility for health. Understanding responsibility as requiring an account is more appropriate in this context because it proceeds from moral agency to establishing what it is people are responsible for. Individuals owe an account for failing to meet an obligation, but not for acting in a morally neutral way. Responsibility for health requires obligation and this presents the major challenge to the use of responsibility in a social function, explaining the insipid telling of patient responsibilities seen in the NHS constitution and elsewhere (Royal College of Surgeons 2005). The normative tension at the heart of professional healthcare is between respect for autonomy and responsibility.

Though the emphasis of autonomy in Anglo-American bioethics has been subjected to recent critique (for example Woods 2007, Walker 2009, Varelius 2006), it remains predominant (Gillon 2003, Edwards 2009), showing little sign of revision in at least its workaday understanding. Valuing, promoting and respecting autonomy above all else is in direct opposition with the notion of obligation. Dworkin (1988 p.41) states;

A moral theory that stresses the supremacy of autonomy will have difficulties with the concept of obligation. As the etymology suggests, to be obliged is to be bound. And to be bound is to have one's will restricted.

The result of this conflict can be seen throughout health promotion. For example in the health warnings on cigarette packets ${ }^{28}$, which are worded in terms of information giving, rather than direct appeals to the moral wrongness of smoking. Of the 14 messages printed on the back of cigarette packets, 11 are written descriptively, offering information, for example, 'smoking clogs the arteries and causes heart attacks and strokes.' Three are prescriptive. (i) Protect children: don't make them breathe your smoke (ii) Smoking is highly addictive: don't start and (iii) Get help to stop smoking: consult your doctor/pharmacist. At the risk of stretching the point a little, (i) merely obliges a smoker to smoke away from children, not to abstain altogether, (ii) is apparently addressed to non-smokers and (iii) obliges the smoker to get help, rather than stop. It has been argued that campaigns which set out to educate about health are, unlike other forms of education, evaluated not in terms of what people know, but in terms of how behaviour changes, because the purpose is an unacceptably morally loaded attempt to change health values to those of the educator (Almark and Tod 2007). The unresolved tension is between the giving of morally

\footnotetext{
${ }^{28}$ The list can be found in annex 1 of Directive 2001/37/EC of the European Parliament and of the Council of $5^{\text {th }}$ June 2001
} 
neutral information in support of autonomous decision making and the attempted revision of morally loaded values and associated obligations.

In the case of smoking these values lead to the view that health education should be directed at trying to get people to give up smoking, but a full rationale for the view that smoking is morally wrong is not offered. Butler's (1993) account of the moral status of smoking is based on harm to others and this also was given as the rationale for legislation prohibiting smoking in public places ${ }^{29}$, and could be offered for the child protecting injunction printed on cigarette packets. These other-regarding considerations are consistent with Mill's harm principle, placing justified restrictions on autonomy. But putting these to one side, whilst noting the beneficial effects to smokers and non smokers of banning smoking in public places (Meyers et al. 2009), we are left with self-regarding reasons not to smoke, (or not to take drugs ${ }^{30}$ or eat cream cakes), and it is here where the imposition of values threatens autonomous decision making. These values are based on a specific conception of health, normatively loaded but neither explained nor justified.

A further problem for 'responsibility for health' used in the sense of social policy, is that even if the issue of having obligations in a general sense in the current environment of valorising personal autonomy was accepted for other-regarding reasons, there remains the problem of identifying and justifying exactly what the obligations are and how they relate to a specific conception of health. A full understanding of 'responsibility for health' requires detailed acceptance of the concept of obligation and detailed justification for its determinative conceptions.

\section{Holding responsible.}

Both the reactive attitudes and accountability versions of responsibility require engagement with our practices of holding individuals responsible. The reactive attitudes account appears to present problems for professional healthcare because healthcare professionals are required by their professional bodies not to have the sorts of attitudes that Strawson claims are definitive of moral responsibility, even of its vicarious expression ${ }^{31}$. The ontological nature of Strawson's claims (and see Stark 2004) are in tension with the normative and regulatory demands made of health professionals, especially noticeable in nursing literature and regulatory documentation, for example concerning discrimination discussed earlier. Positive emotions, (Scott 2000) even love (Stickley and Freshwater 2002), towards patients are lauded in the nursing literature; negative ones are not though neither are fully under conscious control. Regarding the expression of emotion rather than its experience as the morally relevant feature may help but this seems to undermine a claim that (positive) emotions are to be cultivated. The NMC Code (2008) requires that nurses

\footnotetext{
${ }^{29}$ See for example House of Commons Health Committee 2005; para 41 'The justification for the principle of a ban is straightforward: workers have a right to be protected from SHS (second hand smoke).'

30 in the UK a longstanding radio programme asks guests to choose what records they would take if they were marooned alone on a desert island. They are also allowed a single luxury item. If the guest chose a lifetime supply of cigarettes and the means to ignite them would or should health promoters attempt dissuasion?

${ }^{31}$ There are studies in the literature which have found these attitudes in nurses (for example Brown 2006)
} 
'treat people kindly', and this similarly leaves unanswered the question of whether a nurse can treat someone kindly without being a kind person ${ }^{32}$.

The accountability version of responsibility must engage with the question of if and to whom an account is owed. Just because it is fitting that a person gives an account, it does not necessarily follow that an actual account is required or justified (Smith 2007), but if there is a reluctance to blame patients for their behaviour, this may be because of a narrow application of what blame means. Martin (2001) starts a wider categorisation of blame with the simple ascription of wrongdoing to someone who is morally accountable.

It is the NHS which has told us, the public and its patients that we should take some personal responsibility for our health, and this is accepted by many. As the provider of potentially avoidable treatments, it seems consistent that the account is owed to NHS. If this were the case it would fall to healthcare professionals employed by the NHS to hold people to account, but this seems to fall outside the bounds of patientprofessional relationship (Kelley 2005). That is not to say that all moral evaluation of patient's behaviour is disallowed. Positive evaluation in terms of praise could form part of therapeutic relationship, but negative evaluation, that is blame, is not. This therapeutic version of the praise-blame asymmetry is the reverse of that observed in empirical studies (Nelkin 2007, Hindricks 2008). It would also be difficult for a nurse to accept an account from a recalcitrant patient knowing that she may bump into him in the smoking area; a problem acknowledged in the Prime Minister's Commission.

The area where tangible consequences ${ }^{33}$ (liability blame in Martin's (2001) categories) for failure to meet health responsibilities is most plausibly defended is in the suggestion that persons with alcoholic liver failure be denied liver transplantation, or be prioritised lower in the waiting list than those whose disease was not caused by drinking. Though it can be argued that the disease of alcoholism restricts agency, holding responsible in this manner is defended (Glannon 1998) in certain circumstances (Brundy 2007), or as a ‘tie breaker' where other considerations are equal (Thornton 2009). However, official guidance in the UK from the National Institute for Health and Clinical Excellence (2008) states that taking past behaviour into account is relevant only insofar as its continuation threatens the effectiveness of the proposed treatment. The forward looking nature of the official position supports a view that it does not amount to holding responsible, instead merely being one of several criteria that predict the effectiveness of the treatment. Even in this apparently clear case where the causal link between behaviour and disease is settled and the resource is absolutely rather than relatively scarce, the notion of holding patient responsible (at least in this way) is not allowed. ${ }^{34}$

\footnotetext{
${ }^{32}$ This is an expression of the familiar debates between act and agent centred approaches to nursing ethics.

${ }^{33}$ This is of course in addition to the health consequences of undertaking the risky behaviour (Harris 1995).

${ }^{34}$ For a useful and brief paper categorising the various arguments and counter arguments, see Sharkey \& Gillam (2010)
} 
Saying something interesting about responsibility for health

\section{Conclusion}

The discourse of personal responsibility for health is prevalent in the UK and elsewhere, and is set to remain as behaviour-related ill health continues its inexorable increase. The analysis I have offered breaks down the concept into three constituent parts; the agent, an obligation and a consequence, and I have argued that this overarching approach applies to each of the various incomplete conceptions found in the literature. Regarding responsibility for health as fulfilling a social function within professional healthcare is problematic in all three of these constituent parts, most significantly in its occasionally paradoxical relationship with personal autonomy, the respect and promotion of which remains the predominant moral imperative in AngloAmerican bioethics. The analysis offered here remains largely at the conceptual level, and more detailed work is required in the application of the concept of responsibility for health to professional healthcare, both socialised and private. I suspect that this should and will result in a partial and tentative retreat from thoroughgoing respect for autonomy, but at minimum it will require a more nuanced public debate about what the healthy life consists in, how it ought to be maintained, and what obligations are owed to whom, for what reasons, and with what consequences. Currently responsibility for health is conceptually incoherent and if it is to retain its visibility in health policy, this is a situation requiring urgent remedy.

\section{Acknowledgments}

I gratefully acknowledge funding for doctoral study from the University of the West of England, and thank John Coggon and Margaret Brazier for supervision and support at the University of Manchester. 
Saying something interesting about responsibility for health

\section{References}

Allmark P. (2008) An Aristotelian Account of Autonomy. The Journal of Value Inquiry, 42, $41-53$.

Allmark P. \& Tod A. (2007) Philosophy and health education: the case of lung cancer and smoking. In Drummond J.S. and Standish P. (eds) (2007) The Philosophy of Nurse Education. Chapter 2, pp 46-58. Palgrave Macmillan: Basingstoke.

Anderson B.J. Auslander W.F. Jung K.C. Miller. J.P. Santiago J.V. (1990) Assessing family sharing of diabetes responsibilities. Journal of Pediatric Psychology, 15 (4) $477-492$.

Beckwith S. Dickinson A. Kendall S. (2008) The "con" of concept analysis; A discussion paper which explores and critiques the ontological focus, reliability and antecedents of concept analysis frameworks. International Journal of Nursing Studies, 45, 1831 - 1841.

Boorman S. (2009) NHS Health and Well-being. Department of Health: London.

Boorse C. (1975) On the distinction between disease and illness. Philosophy and Public Affairs, 5, 49-68.

Boorse C. (1977) Health as a theoretical concept. Philosophy of Science, 44, 542573.

Brazier M. \& Cave E. (2011) Medicine, Patients and the Law (fifth edition). Penguin Books: London.

Brown I. (2006) Nurses' attitudes towards adult patients who are obese: literature review. Journal of Advanced Nursing, 53 (2), 221 - 232.

Brundy, D. (2007) Are alcoholics less deserving of liver transplants? Hastings Centre Report, 37 (1) $41-47$.

Burns K. \& Bechara A. (2007) Decision making and Free Will: A neuroscience perspective. Behavioral Sciences and The Law, 25, 263 - 280.

Butler K. (1993) The moral status of smoking. Social Theory and Practice 19 (1) 126.

Butland B. Jeb S. Kopleman P. Mcpherson K. Thomas S. Mardell J. and Parry V. (2007) Foresight. Tackling Obesities: Future Choices - Project Report. Department of innovation, Universities and Skills: London.

Cane P. (2002) Responsibility in Law and Morality. Hart Publishing: Oxford.

Coggon J. (2007) Varied and unprincipled understanding of autonomy in English law: Justifiable inconsistency or blinkered moralism? Health Care Analyis, 15, 235 -255 . 
Saying something interesting about responsibility for health

Department of Health (2008) Healthy weight, healthy lives. A cross government strategy for England. Department of Health: London.

Department of Health (2009) The NHS Constitution. Department of Health: London.

Department of Health (2010) Handbook to the NHS Constitution in England. Department of Health: London.

Department of Health (2011) The Government's Response to the Recommendations in Front Line Care. Department of Health: London.

Dubbink W. \& Smith J. (2011) A Political Account of Corporate Moral Responsibility. Ethical Theory and Moral Practice, 14, 223 - 246.

Dworkin G. (1988) The theory and practice of autonomy. Cambridge University Press: Cambridge.

Edwards S.L. (2009) Nursing Ethics; A Principle Based Approach. Palgrave Macmillan: Basingstoke.

Fischer J.M. (1987) Responsiveness and Moral Responsibility. In Pereboom, D (ed) (1997) Free Will. Chapter 17, p214 - 242. Hackett Publishing: Indianapolis.

Fischer J.M. \& Ravizza M. (1998) Responsibility and Control: A theory of moral responsibility. Cambridge: Cambridge University Press.

Foddy B. (2011) Addicted to Food, Hungry for Drugs. Neuroethics, 4 (2) 79 - 89.

Gallie W.B (1956) Essentially Contested Concepts. Proceedings of the Aristotelian Society, 56, 167 - 198.

General Medical Council (2006). Good Medical Practice. General Medical Council: London.

Gillon R. (2003) Ethics needs principles - four can encompass the rest - and respect for autonomy should be 'first among equals' Journal of Medical Ethics 29, 309-312.

Glannnon, W. (1998) Responsibility, alcoholism, and liver transplantation. Journal of Medicine and Philosophy 23 (1) 31 - 49.

Guttman N. \& Ressler W.H. (2001) On being responsible: Ethical Issues in appeals to Personal Responsibility in Health Campaigns. Journal of Health Communication, 6, 117-136.

Hanna K.M. \& Decker C.L. (2009) A concept analysis: Assuming responsibility for self care among adolescents with type 1 diabetes. Journal for Specialists in Paediatric Nursing, 15 (2) $99-110$. 
Saying something interesting about responsibility for health

Harris J. (1980) Violence and Responsibility. Routledge and Kagan Paul: London.

Harris J. (1995) Could we hold people responsible for their own adverse health? Journal of Contemporary Health law and Policy, 12, 147 - 153.

Hart H.L.A. (1968) Punishment and Responsibility. Essays in the Philosophy of law. Clarenden Press: Oxford.

Hellman D. (2008) When is Discrimination Wrong? Harvard University Press: Cambridge, Massachusetts.

Hindricks F. (2008) Intentional action and the praise-blame asymmetry. The Philosophical Quarterly, 58 (233) 630-641.

Houmanfar R. Maglieri K.A. Roman H.R. Ward, T.A. (2009) Behavioral Contracting in O'Donohue W.T. and Fisher J.E. (Eds) (2009). Cognitive Behavioural Therapy: Applying Empirically Supported Techniques in Your Practice. Chapter 8, p 53 - 59. John Wiley and Sons: Hoboken, New Jersey.

House of Commons Health Committee (2005) Smoking in Public Places; First report of session 2005 - 2006. The Stationary Office limited: London [on line] http://www.publications.parliament.uk/pa/cm200506/cmselect/cmhealth/485/4 85.pdf (last accessed 4th November 2011).

Kahn L. (2011). Moral Blameworthiness and the Reactive Attitudes. Ethical Theory and Moral Practice, 14 (2) 131-142.

Kane R. (2005) A Contemporary Introduction to Freewill. Oxford University Press: Oxford.

Kelley M. (2005) Limits on Patient Responsibility. Journal of Medicine and Philosophy, 30, 189-206.

King's Fund (2004) Public attitudes to public health policy. King's Fund: London.

Korsgaard C.M. (1992) Creating the Kingdom of Ends: Reciprocity and responsibility in personal relations. Philosophical Perspectives, 6, 305-332.

Levitt M. \& Manson N. (2007) My genes made me do it? The implications of behavioural genetics for responsibility and blame. Health Care Analysis, 15, $33-40$.

MacClean J. (1999) 'I did it!' Canadian Living July, 73.

Malatravers M. (2007) Responsibility and Justice. Polity press: Cambridge.

Manley K. Watts C. Cunningham G. Davies J (2011) Principles of Nursing Practice: development and implementation. Nursing Standard, 25 (27) 35-37. 
Saying something interesting about responsibility for health

Martin M. (2001) Responsibility for health and blaming victims. Journal of Medical Humanities, 22 (2) 95-114.

McKnight C. (2003) Medicine as an essentially contested concept. Journal of Medical Ethics, 29, 261-262.

Miller K. (2010) On the concept of sexual perversion. The Philosophical Quarterly, 60 (241) 808-830.

Meyers D.G. Neuberger J.S. He J. (2009) Cardiovascular effect of bans on smoking in public places: a systematic review and meta-analysis. Journal of the American College of Cardiology 54 (14) 1249-1255.

Moreau S. (2010) What is Discrimination? Philosophy and Public Affairs, 38 (2) 143179.

National Institute for Health and Clinical Excellence (2008) Social Value Judgements: principles for the development of NICE guidance. (Second edition). National Institute for Health and Clinical Excellence: London.

Nelkin D.K. (2007) Do we have a coherent set of intuitions about moral responsibility? Midwest Studies in Philosophy, XXXI, 243-259.

NHS Scotland. (2006) The NHS and you; what you can expect from us. What we expect from you. [on line] http://www.healthworkerstandards.scot.nhs.uk/Documents/NHSandYou.pdf (last accessed 4th November 2011).

Nordenfelt L. (1993) Concepts for health and their consequences for the delivery of health care. Theoretical Medicine, 14, 277-285.

Nordenfeld L. (1996) On the notion of health as ability. Scandinavian Journal of occupational Therapy, 3, 101-105.

Nordenfelt L. (2007) The concepts of health and illness revisited. Medicine, Health care and Philosophy, 10, 5-10.

Nursing and Midwifery Council (2008) The code: Standards of conduct, performance and ethics for nurses and midwives. Nursing and Midwifery Council: London.

Olinder A.L. Nyhlin K.T. Smide B. (2011) Clarifying responsibility for self management of diabetes in adolescents using insulin pumps - a qualitative study. Journal of Advanced Nursing, 67 (7) 1547-1557.

Oshana M.A.L. (1997) Ascriptions of responsibility. American Philosophical Quarterly, 34 (1) 71-82.

Oshana M.A.L. (1998) Personal Autonomy and Society. Journal of Social Philosophy 29, $8-102$. 
Saying something interesting about responsibility for health

Oshana M.A.L. (2002) The misguided marriage of responsibility and autonomy. The Journal of Ethics, 6, 261- 280.

Paley J. (1996) How not to clarify concepts in nursing. Journal of Advanced Nursing 24, $572-578$.

Prime Minister's Commission on the Future of Nursing and Midwifery in England (2010) Front Line Care. Prime Minister's Commission on the Future of Nursing and Midwifery in England: London.

Raphael D. (2006) Social determinants of health: present status, unanswered questions, and future directions. International Journal of Health Services, 36 (4) 651-677.

Resier S.J. (1985) Responsibility for personal health : A historical perspective. Journal of Medicine and Philosophy, 10, 7 - 17.

Risjord M. (2009) Rethinking Concept Analysis. Journal of Advanced Nursing 65 (3) $684-691$.

Roy S.C. (2008) 'Taking charge of your health': discourses of responsibility in English Canadian women's magazines. Sociology of Health and Illness, 30 (3) $463-477$.

Royal College of Surgeons of England (2005) Patient rights and responsibilities. Royal College of Surgeons of England: London.

Ruben D-H (2010) W.B.Gallie and essentially Contested Concepts. Philosophical Papers, 39 (2) $257-270$.

Scott P.A. (2000) Emotion, moral perception, and nursing practice. Nursing Philosophy, 1 (2) 123 - 133.

Schmidt H. (2007) Personal Responsibility for Health - Developments under the German healthcare reform 2007. European Journal of Health Law, 14, 241 250 .

Sharkey K. \& Gillam L. (2010) Should patients with self-inflicted illness receive lower priority in access to health care resources? Mapping out the debate. Journal of Medical Ethics, 36, 661-665.

Sie M. (2005) Justifying Blame. Why freewill matters and why it does not. Rodophi: Amsterdam.

Smith P. (2002) Drugs, Morality and the Law. Journal of Applied Philosophy, 19 (3) 233- 244.

Stark S. (2004) Emotions and the Ontology of Moral Value. The Journal of Value Enquiry 38, 355-374. 
Saying something interesting about responsibility for health

Stickley T. \& Freshwater, D. (2002) The art of loving and the therapeutic relationship. Nursing Inquiry, 9 (4) 250-256.

Stirrat G.M. Johnston C. Gillon R. Boyd, K. (2010) Medical ethics and law for doctors of tomorrow: the 1998 Consensus Statement updated. Journal of Medical Ethics, 36; 55-60.

Strawson P. (1962) Freedom and Resentment. Proceedings of the British Academy 48, 1-25. Reprinted in Watson, G (Ed) (2003). Free Will (second edition). Chapter 4, p 72 - 93 Oxford University Press: Oxford.

Sutherland S. (1992) Irrationality. Pinter and Martin: London.

Ter Meulen R. and Maarse H. (2008) Increasing Individual Responsibility in Dutch Health Care: Is Solidarity Losing Ground? Journal of Medicine and Philosophy, 33, $262-279$.

Thaler R.H., Sunstein C.R. (2009) Nudge; Improving Decisions About Health Wealth and Happiness. Penguin Books: London.

Thornton V. (2009) Who gets the liver transplant? The use of responsibility as a tie breaker. Journal of Medical Ethics 35, 739 - 742.

United Nations Educational Scientific and Cultural Organisation (UNESCO) (2008) Bioethics Core Curriculum. Section 1: Syllabus. [on line] http://unesdoc.unesco.org/images/0016/001636/163613e.pdf (last accessed 4th November 2011).

Van Inwagen P. (1975) The incompatibility of free will and determinism. Philosophical Studies, 27, 185-199.

Varelius J. (2006) The value of Autonomy in medical ethics. Medicine Health Care and Philosophy, 9, 377-388.

Walker L.O. \& Avant K.C. (2011) Strategies for Theory Construction in Nursing (Fifth edition) Pearson Education: Upper Saddle River.

Walker R.L. (2009) Medical ethics needs a new view of autonomy. Journal of Medicine and Philosophy, 33; $594-608$.

Wallace R.J. (1994) Responsibility and the Moral Sentiments. Harvard University Press: Cambridge, Massachusetts.

Waller B.N. (2005) Responsibility and Health. Cambridge Quarterly of Healthcare Ethics, 14, 177-188.

Wedgwood R. (2006) The meaning of ought. In Landau-Shafer, R (2006) Oxford Studies in Metaethics volume 1. Chapter 5, pp 127 - 160. Oxford University Press: Oxford. 
Saying something interesting about responsibility for health

Williams G. (2008) Responsibility as Virtue. Ethical Theory and Moral Practice, 11, $455-470$.

Wilmot S. (2000) Corporate moral responsibility in health care. Medicine Health Care and Philosophy, 3, $139-146$.

Woods S. (2007) Death's Dominion; Ethics at the End of Life. Open University Press: Maidenhead. 